Fermentology • The Book of Fermentology

\title{
The Origins of Yoghurt Microbes [essay]
}

Jessica Hendy, Matthäus Rest, Christina Warinner

Published on: Nov 25, 2021

DOI: $10.52750 / 605475$

License: Creative Commons Attribution 4.0 International License (CC-BY 4.0). 
Sour milk products, such as yogurt, are foods that connect the vast Eurasian continent - from the northern pastures of Mongolia to the mountains of Bulgaria to the fjords of Scandinavia. While sour milk products may differ in taste and texture, they are all made using the same fundamental principle: fermentation by lactic acid bacteria. Lactic acid bacteria (LAB) - present naturally in milk - are a diverse group of Grampositive bacteria that specialize in fermenting (digesting) the milk sugar lactose. As a by-product of fermentation, these bacteria produce lactic acid, and in doing so, they create a unique ecosystem for themselves. Most bacteria, including many species that are pathogenic to humans, are killed or inhibited by even weak acids, but LAB can thrive in acidic environments as low as pH 3 (about the acidity of household vinegar). The manipulation of LAB to acidify milk also has culinary and nutritional consequences beyond inhibiting the growth of pathogens. In yogurt, perhaps the best-known sour milk product, the acidic environment causes caseins (one of the main protein groups in milk) to clump together, creating yogurt's characteristic thick texture, and the lactic acid and acetaldehyde produced by LAB give yogurt its tangy taste[1]]. LAB fermentation also increases the vitamin content of milk, in particular by increasing the levels of $\mathrm{B}$ and $\mathrm{K}$ vitamins [2] ]. With up to several million live cells in a typical serving, yogurt is not just a food - it is a living ecosystem.

Yogurt is conventionally made by heating milk above $140^{\circ} \mathrm{F} / 60^{\circ} \mathrm{C}$, cooling and adding LAB starter culture, and fermenting at a desired temperature [ㅍ]. 
The initial heating step concentrates and partially curdles (denatures) the milk proteins, creating a thicker texture. In commercial settings, manufacturers also typically add additional milk proteins in the form of milk powder, as well as other components, such as emulsifiers, stabilizers and sweeteners to create a consistent product that overcomes natural variations in milk composition. Heating is also a form of microbial regulation. Heating above $140^{\circ} \mathrm{F} / 60^{\circ} \mathrm{C}$ kills bacteria and fungi (yeasts and molds) living in milk so that when the

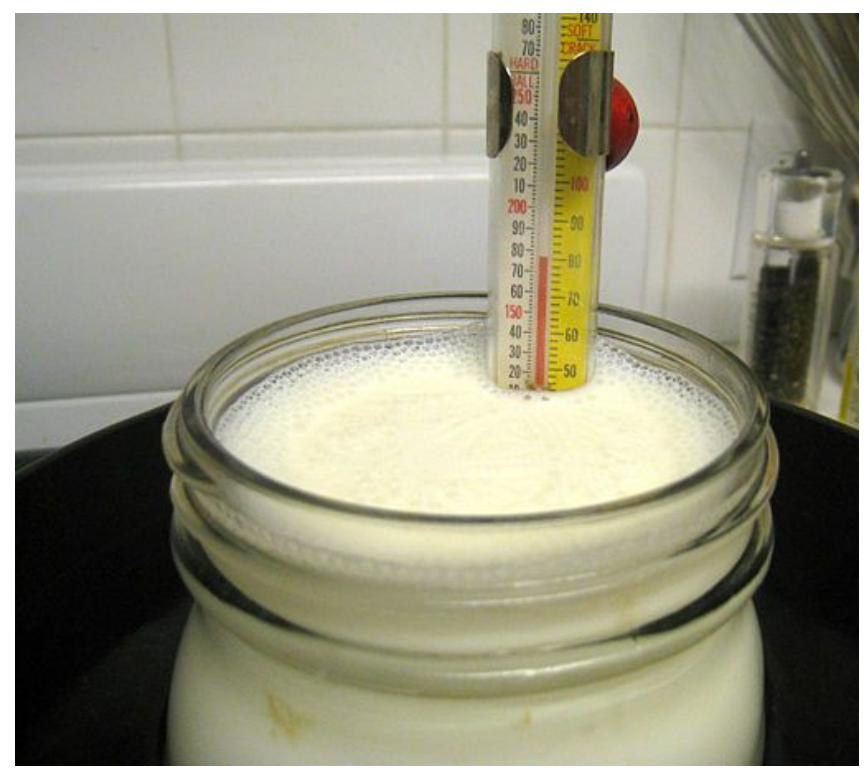

Image from Dvortygirl, CC BY-SA 3.0, via Wikimedia Commons starter culture is later added only these desired LAB bacteria will grow and flourish. In commercial contexts, starter cultures generally take the form of laboratory-produced, freeze-dried bacteria, but for home-made yogurt production the starter is often simply a portion of the previous batch of yogurt, a technique known as "backslopping". When unheated raw milk is used, yogurt can also form spontaneously due to lactic acid bacteria naturally present in milk, without the need for any starter culture. But where do the microbes in the backslop originally come from? The short answer is "bodies," those of animals and those of plants.

Lactic acid bacteria are composed of two main genera, Lactococcus and Lactobacillus, but also include Leuconostoc, Streptococcus, Bifidobacterium and Enterococcus species. These bacteria thrive under different conditions, meaning that the microbial composition of a particular dairy food is reflective of how it was made. For example, Lactobacillus and Streptococcus are generally heat-loving (thermophilic) and hence prefer warm temperatures for fermentation $\left(113^{\circ} \mathrm{F} / 45^{\circ} \mathrm{C}\right)$. They are characteristic of the tart yogurts originating from Eastern Europe, Turkey, and the Middle East. By contrast, Leuconostoc and Lactococcus species like moderate temperatures (they are mesophilic) and hence thrive under relatively cooler temperatures $\left(85^{\circ} \mathrm{F} / 30^{\circ} \mathrm{C}\right)$. They are found in products like crème fraiche and sour cream. Leuconostoc is also a component of the symbiotic culture of bacteria and yeast (SCOBY) found in kefir. 
The thermal preferences of different LAB species in part reflect their evolutionary origin. For example, genetic evidence suggests that Streptococcus thermophilus, an important yogurt LAB that grows best near body temperature, likely evolved from Streptococcus salivarius or Streptococcus vestibularis, two closely related species found in saliva [ㄴ] $]$. To put it more plainly, saliva microbes colonized yoghurts and then, once in yoghurt, evolved to thrive in the conditions the yoghurt presented.

Likewise, Lactobacillus, Bifidobacterium, and Enterococcus are genera of primarily thermophilic LAB that consist mainly of species inhabiting the mammalian gastrointestinal and urogenital tracts. Species of these genera colonized (and continue to colonize) yoghurt, whether from human guts or those of animals associated with yoghurt making, whether they be cows, sheep, horses, or even camels [ㅁ].

By contrast, members of Lactococcus and Leuconostoc are generally live on plants in nature and grow best at ambient temperatures, like those they would experience on the plants []]. Leuconostoc mesenteroides, the most important culinary Leuconostoc, is the traditional LAB responsible for initiating fermentation in the production of sauerkraut and kimchi, in addition to its use in dairy production.

Although a wide range of lactic acid bacteria is found in raw milk [7], commercially produced yogurts generally rely on just a handful of specific subspecies, and fermentation is tightly controlled. In modern industrial-scale production, yogurt is typically made using just two bacterial species, Streptococcus thermophilus and Lactobacillus delbrueckii subspecies bulgaricus. These species are so crucial to the creation of this product that in the United States yogurt cannot be called yogurt unless it contains these specific bacteria (FDA 21CFR131.200). As already mentioned, Streptococcus thermophilus originally evolved from a saliva microbe. The story of Lactobacillus delbrueckii subspecies bulgaricus is even more interesting (and bodily).

\section{Citations}

1. 
Josephsen, Jytte and Jespersen, Lene." Starter cultures and fermented products.” In Handbook of Food and Beverage Fermentation Technology, edited by Y. H. Hui, Lisbeth Meunier-Goddik, Jytte Josephsen, Wai-Kit Nip, Peggy S. Stanfield. Marcel Dekker, Inc. New York, 2004.

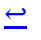

2.

LeBlanc, J. G., J. E. Laiño, M. Juarez del Valle, V. Vannini, D. van Sinderen, M. P. Taranto, G. Font de Valdez, G. Savoy de Giori, and F. Sesma. 2011. "B-Group Vitamin Production by Lactic Acid Bacteria--Current Knowledge and Potential Applications.” Journal of Applied Microbiology 111 (6): 1297-1309.

Morishita, T., N. Tamura, T. Makino, and S. Kudo. 1999. "Production of Menaquinones by Lactic Acid Bacteria." Journal of Dairy Science 82 (9): 1897-1903.

$\underline{\underline{ }}$

3. Sfakianakis, Panagiotis, and Constatnina Tzia. 2014. "Conventional and Innovative Processing of Milk for Yogurt Manufacture; Development of Texture and Flavor: A Review." Foods 3 (1): 176-93. $ヒ$

4. Delorme, Christine, Anne-Laure Abraham, Pierre Renault, and Eric Guédon. 2015. “Genomics of Streptococcus Salivarius, a Major Human Commensal.” Infection, Genetics and Evolution 33 (July): 381-92.

5. Guchte, M. van de, S. Penaud, C. Grimaldi, V. Barbe, K. Bryson, P. Nicolas, C. Robert, et al. 2006. "The Complete Genome Sequence of Lactobacillus Bulgaricus Reveals Extensive and Ongoing Reductive Evolution." Proceedings of the National Academy of Sciences of the United States of America 103 (24): 9274-79.

6. Nomura, M., M. Kobayashi, T. Narita, H. Kimoto-Nira, and T. Okamoto. 2006. "Phenotypic and Molecular Characterization of Lactococcus Lactis from Milk and Plants." Journal of Applied Microbiology 101 (2): 396-405. $\subseteq$

7. O’Sullivan, Orla, and Paul D. Cotter. 2017. “Chapter 12 - Microbiota of Raw Milk and Raw Milk Cheeses." In Cheese (Fourth Edition), 301-16. San Diego: Academic Press. $ヒ$ 